\title{
The Roles of Seeking Psychological Help, Self-stigma and Self-construal in Prediction of Attitudes towards Seeking Psychological Help
}

\author{
Oya Onat Kocabıyık (Corresponding author) \\ Department of Psychology, Faculty of Arts and Sciences \\ Tekirdağ Namık Kemal University, Tekirdağ, Turkey \\ E-mail: okocabiyik@nku.edu.tr
}

Seda Donat Bacıoğlu

Department of Guidance and Counseling, Faculty of Education

Trakya University, Edirne, Turkey

Received: December 11, 2020 Accepted: January 10, 2020 Published: January 21, 2021

doi:10.5296/jei.v7i1.18060 URL: https://doi.org/10.5296/jei.v7i1.18060

\begin{abstract}
In this study, the purpose is to examine to what extent the individuals' self-stigma and self-construal predict their attitudes towards seeking psychological help. The sample group of the study was made of 377 adults aged 20-50 years. The data obtained from the scales based on self-reports of the participants were analyzed. Findings showed that there is a positive significant relationship between the attitude towards seeking psychological help and self-stigma. Self-stigma positively predicted the attitudes towards seeking psychological help; on the other hand, individual self-construal negatively predicted the attitudes towards seeking psychological help. In light of these findings, it is recommended that comparative studies in terms of self-stigma and self-construal according to gender can be conducted with different socio-cultural characteristics. Also, the persons of who have received or applied to counseling from psychological counseling centers, their self-stigma and self-construals levels can be investigated in later studies.
\end{abstract}

Keywords: Seeking psychological help, Self-stigma, Self-construal, Adult 


\section{Introduction}

Individuals may need professional help when they try to cope with anxiety after they experienced the incident (Türküm, 2000). To begin Professional help process, the perception of problem by the individual and preferring the help source is one of the most important steps (Pescosolido, 1992). In this process, how the individual perceives the problem is becoming important and it causes to take the decision of how and whom they get help or whether they get help (Serim \& Çankaya, 2015). The process of receiving help decision of the individuals begins when exploring they have difficulties or their mental health are in danger, they have problems and they are in need of a help. Yet, whether individuals act to get help or not is associated with their attitudes towards seeking help. Determining how the individuals will cope with the problem or deciding in what way they will take are substantially related to their attitudes towards help (Serim \& Çankaya, 2015). It could be said that especially stigmatization has a significant effect among the elements affecting attitudes towards seeking help of individuals. When examining stigmatization concept, it is seen that there are two types as social stigma and self-stigma (Corrigan, 2004). The most important reason for individuals to avoid seeking psychological help is that they have the idea of would be stigmatized by the society if they indicate their need for psychological help. This idea can lead the individual to stigmatize themselves by internalizing it (Acun-Kapıkıran \& Kapıkıran, 2013; Bilge \& Çam, 2010; Vogel et al., 2013). Self-stigmatized individuals often believe that they are bad, weak and worthless, they do not trust themselves and their skills, even if they have an obvious problem, this may have an effect that keeps individuals away from receiving help (Corrigan, Roe, \& Tsang, 2011; Vogel et al., 2013). Similarly, Bilge and Çam (2010) stated that the perception of the society about psychological problems affected the seeking of psychological help behaviors of the individuals living in that society; it was stated that despite the psychological problems, getting the professional help of the individual could be delayed and psychological problems could reach more serious dimensions.

For this reason, it is seen that the self-construal of the individual has a significant effect on the factors affecting attitudes towards seeking psychological help. When the definitions related to self-construal are examined in the literature; as a result of the individual's relations with other individuals, but different emotions, thoughts and behaviors that are distinct from them are defined as self-perception ways that are shaped by the culture that they live in (Markus \& Kitayama, 1991; Singelis, 1994; Constantine, 2001). Self-construal, whose development depends on the culture of the individual, is examined in three different dimensions as individual, relational and collective (Kashima \& Hardie, 2000). Of individuals who have individual self-construal, the knowledge about the self is characterized by distinctness and autonomy, and the emphasis is on being independent from other individuals. Of individuals who have collective self-construal, knowledge about the self is formed within the framework of a sense of belonging to the group. Of individuals who have a relational self-construal, the knowledge about the self is structured within the framework close relationships rather than the sense of belonging. Relational self-construal is defined as personal trait of which satisfactory attachments are important and it expresses dependence to other individuals (Cross, Bacon, \& Morris, 2000). In individualist societies, individual 
self-construal is formed especially characterizing autonomous self traits, whereas in communal societies, collective self-construal is formed characterizing dependency (Markus \& Kitayama, 1991).

For individuals who have collective self-construal, because of communicating compatibly with other individuals and maintaining is important, it prevents individuals from expressing their feelings (Trommsdorff \& Rothbaum, 2008). When the relationship between collective self-construal and emotion regulation, especially anger regulation is examined, it is emphasized that suppressing anger causes fewer depressive symptoms in individuals with high level of dependent self-construal compared to individuals with low level of dependent self-construal (Cheung \& Park, 2010; Park \& Kim, 2012). In other studies (Cheung \& Park, 2010; Su, Lee \& Oishi, 2012), similarly, it is found that individuals who have high level of dependent self-construal such as Singaporean Chinese and Asian Americans show fewer depressive symptoms in case of suppression of anger compared to European Americans who have high levels of individual self-construal. It is stated that because self of the individuals, who have collective self-construal, gains meaning in the context of wide social relations, those individuals have a tendency to suppress their negative feelings and not having a tendency to receive psychological help in order to maintain social cohesion (Park \& Kim, 2012). In a study conducted on the relationship between individual self-construal and attitude towards seeking psychological help (Helmes \& Gallou, 2014), there was a positive relationship between two variables. Similarly, in the study conducted by Yalçın (2016), it is emphasized that individuals with individual self-construal experience less fear of social stigma and therefore, they have a more positive attitude towards seeking professional psychological help than others. However, these explanations about self-construal (Bond \& Smith, 1996) are considered as "independent" and "codependence" as opposed poles by conceptualizing it with a Western view (Kağıtçıbaşı, 2010). Later studies showed that these two developmental pathways are the basic human need (Ryan \& Deci, 2000) that autonomy and relationality are not opposite poles (Cross \& Madson, 1997; Matsumoto, 2002). Nowadays, having different identifications about self-construal, researchers have brought forward triple self-construal model by emphasizing triple structure than binary self-construal (İmamoğlu, 1998; Kağıtçıbaşı, 1996). Kağıtçıbaşı (1996) asserted that changes in the system of values that come along with socioeconomic improvement would not create a transition to individualism and independency; this would form a transition from dependency model through codependency model. In such a relational model, autonomy and family loyalty can be combined. For this reason, on one hand, the individual can stay loyal to one's family and on the other hand one can be autonomous. This may affect the attitudes of individuals to seeking psychological help. In short, individuals' attitudes of seeking help are influenced by traditions, perception of reality and identification process (Serim \& Çankaya, 2015). Therefore, in this study, it is aimed to examine in what extent the individuals' self-stigma and self-construal predict their attitudes towards seeking psychological help.

\section{Method}

This research was designed according to the correlational design of quantitative research methods. 


\subsection{Participants}

The sample group of the research was made of 377 adults who have been studying at "Pedagogical Formation Certificate Course" in Trakya University Education Faculty. 292 of the participants were female $(77.5 \%)$ and 85 of them were male $(22.5 \%) ; 101$ of them were graduate $(26.8 \%)$ and 276 were undergraduate $(73.2 \%)$. The age of individuals in the sample group ranged between 20 and 50 and average of age was $24.31(\mathrm{SS}=5.02) .326$ of the participants were single $(86.5 \%), 49$ of them were married $(13.0 \%)$ and 2 of them were divorced $(0.5 \%)$.

\subsection{Data Collection Tools}

Attitudes Towards Seeking Psychological Help Scale-Short Form: Developed by Türküm (2001), Attitudes Towards Seeking Psychological Help Scale (ATSPH) is a five-point Likert type with total 18 -item scale aiming to measure the individuals' attitudes towards seeking professional psychological help. High level of positive attitudes towards seeking psychological help is directly proportional to the high scores obtained from the scale. Cronbach Alpha internal consistency coefficient is .90, test-retest reliability is .77 which was applied in 10 weeks' intervals (Türküm, 2001).

Relational-Individual-Collective Self Aspects Scale (RIC): Developed by Kashima and Hardie (2000), RIC aims to measure individuals' relational, individual and collective self-aspects. There are 10 items in the scale to measure each self-aspect and there are 30 items in total. The internal consistency coefficients of the original scale were found as .72 for the individualism subscale, .81 for the relationality subscale and .78 for the collectivity subscale. Ercan (2011) conducted the study of Turkish adaptation of RIC. In the Turkish version of the scale, there are nine items in each subscale and the scale consists of 27 items in total. The internal consistency coefficients of the Turkish version of the scale were .73 for the individualism subscale, .68 for the relationality subscale and .77 for the collectivity subscale.

Self-Stigma of Seeking Help Scale (SSOSH): Developed by Vogel, Wade, and Haake (2006), SSOSH is a five-point Likert type with 10-item in total and one-dimensional scale. Some items of the scale are reverse scored and high score refers to high level of self-stigma in seeking help. The internal consistency coefficient of the scale was .91 and the test-retest reliability was calculated as .72 in two months intervals. The adaptation study of SSOSH into Turkish was done by Acun-Kapıkıran and Kapıkıran (2013). In order to determine the internal consistency of the scale for reliability, Cronbach Alpha coefficient was calculated and the total internal consistency of the scale was found as .71 which was acceptable.

\subsection{Data Analysis}

Correlation analysis and simple and multiple regression analyzes were performed to see the relationships between dependent and independent variables.

\section{Results}

In the study, correlation analysis was performed to see the relationships between dependent and independent variables. Table 1 presented the correlation values between variables, means 
related to variables and standard deviation values.

Table 1. Descriptive statistics regarding attitudes towards seeking psychological help, self-stigma, individuality, relationality and collectivity and correlation values between these variables

\begin{tabular}{|l|l|l|l|l|l|l|l|}
\hline & $\overline{\boldsymbol{x}}$ & $\boldsymbol{s}$ & $\mathbf{1}$ & $\mathbf{2}$ & $\mathbf{3}$ & $\mathbf{4}$ & $\mathbf{5}$ \\
\hline 1. Attitudes towards seeking psychological help & 34.49 & 9.42 & 1 & & & & \\
\hline 2. Self-Stigma & 22.92 & 5.56 & $.55^{* *}$ & 1 & & & \\
\hline 3. Individuality & 54.08 & 6.05 & $-.22^{* *}$ & $-.16^{* *}$ & 1 & & \\
\hline 4. Relationality & 52.09 & 6.82 & $-.14^{* *}$ & -.03 & $.57^{* *}$ & 1 & \\
\hline 5. Collectivity & 49.17 & 7.99 & -.06 & .04 & $.46^{* *}$ & $.66^{* *}$ & 1 \\
\hline
\end{tabular}

Note. $* * \mathrm{p}<.01$.

As seen in Table 1, there was a statistical positive significant relationship between attitudes towards seeking psychological help and self-stigma $(\mathrm{r}=.55, \mathrm{p}<.01)$. As attitudes towards seeking psychological help increased, attitudes towards self-stigma increased as well.

There was a negative significant relationship between attitudes towards seeking psychological help and individuality $(\mathrm{r}=-.22, \mathrm{p}<.01)$ and relationality $(\mathrm{r}=-.14, \mathrm{p}<.01)$. As attitudes towards seeking psychological help increased, scores of individuality and relationality decreased. However, any significant relationship could not found between attitudes towards seeking psychological help and collective self-construal $(r=-.06, p>.05)$.

Table 2. Simple regression results regarding prediction of self-stigma to attitudes towards seeking psychological help

\begin{tabular}{|l|l|l|l|l|l|}
\hline Variable & $B$ & $S H B$ & $\beta$ & $t$ & $p$ \\
\hline Fixed & 13.14 & 1.73 & & 7.62 & $<.001$ \\
\hline Self-Stigma & .93 & .07 & .55 & 12.73 & $<.001$ \\
\hline
\end{tabular}

Note. $\mathrm{R}^{2}=.30, \mathrm{~F}(1,375)=162.15, \mathrm{p}<.001$.

As seen in Table 2, self-stigma positively and significantly predicted attitudes towards seeking psychological help $(\beta=.55)$ and explained $30 \%\left(\mathrm{R}^{2}=.30\right)$ of attitudes towards seeking psychological help $[\mathrm{F}(1,375)=162.15, \mathrm{p}<.001]$. 
Table 3. Multiple regression analysis results regarding prediction of sub-dimensions of self-construal to attitudes towards seeking psychological help

\begin{tabular}{|l|l|l|l|l|l|}
\hline Variable & $B$ & $S H B$ & $\beta$ & $t$ & $p$ \\
\hline (Constant) & 53.47 & 4.53 & & 11.81 & $<.001$ \\
\hline Individuality & -.34 & .10 & -.22 & -3.57 & $<.001$ \\
\hline Relationality & -.12 & .10 & -.08 & -1.14 & .255 \\
\hline Collectivity & .11 & .08 & .10 & 1.42 & .155 \\
\hline
\end{tabular}

Note. $\mathrm{R}^{2}=.06, \mathrm{~F}(3,373)=7.30, \mathrm{p}<.001$.

As seen in Table 3, self-construal significantly predicted attitudes towards seeking psychological help and explained $6 \%\left(\mathrm{R}^{2}=.06\right)$ of attitudes towards seeking psychological help $[\mathrm{F}(3,373)=7.297, \mathrm{p}<.001]$. In addition, relationality $(\beta=-.08, \mathrm{p}>.05)$ and collectivity $(\beta=.10, p>.05)$ did not have any significant effect; however, individual self-aspect was the only significant predictor $(\beta=-.22, \mathrm{p}<.001)$. Accordingly, as individual self-aspect increased, attitudes towards seeking psychological help decreased.

\section{Discussion}

In this study, it was examined to what extent the individuals' self-stigma and self-construals predict their attitudes towards seeking psychological help. According to the findings, there is a positive significant relationship between the attitude towards seeking psychological help and self-stigma, as the attitude towards seeking psychological help increases, the attitude towards self-stigma increases. Self-stigma positively and significantly predicts attitudes towards seeking psychological help and explains 30\% of attitudes towards seeking psychological help. Some studies carried on this subject (Corrigan, 2004; Vogel, Wade, \& Haake, 2006) indicate that expectations of individuals regarding psychological help would be beneficial will reduce self-stigma. However, social perceptions to psychological problems affect the individual's view of getting help, and despite of psychological problems, the individual can delay receiving expert help. Although individuals need psychological help, they may be refraining from receiving psychological help due to negative social perceptions (Acun-Kapıkıran \& Kapıkıran, 2013). When individuals internalize the social stigma, self-stigma also emerges and as a result of it, individuals prefer to stay away from using psychological help services (Corrigan, 2004). Individuals are even more distressed being stigmatized by individuals they are interacting with than those who they know remotely, and this is more decisive whether seeking help or not (Vogel et al., 2013). Therefore, even if individuals' attitudes towards seeking help are positive, this situation may lead to increase self-stigma rather than reducing it. In the study by Vauth, Kleim, Wirtz, and Corrigan (2007), supporting the result of the study, it was stated that stigmatization and devaluation continued even if the received psychological help was effective.

Another finding obtained from the study is that there is a negative significant relationship between attitudes towards seeking psychological help and individuality and relationality. As 
the attitudes towards seeking psychological help increases, individuality and relationality scores decrease. Self-construal significantly predicts attitudes towards seeking psychological help, while relationality and collectivity do not have a significant effect; individuality self-aspect explains $6 \%$ of attitudes of seeking psychological help.

In a study investigating the relationship between individuality and seeking psychological help (Helmes \& Gallou, 2014), a positive relationship was found between the two variables. Similarly, in the study conducted by Yalçın (2016), it is emphasized that individuals with individual self-construal experience less fear of social stigma and therefore, they have a more positive attitude towards seeking professional psychological help than others. However, according to the results of this study, the attitude towards seeking psychological help decreases as the individual self-construal increases. It is thought that there may be several reasons for the result to come out. The first of them is related to the general reluctance of people to receive professional psychological help (Andrews, Issakidis, \& Carter, 2001). Examined the studies on this subject in the literature (Jorm, 2000; Kessler et al., 1994; Vogel, Wade, \& Haake, 2006), it was reported that regardless of ethnicity, individuals prefer self-help about mental health problems. Another reason is cultural factors; rather than evaluating autonomy and relativity as opposed poles, especially in Turkish society, it is based on the fact that a transition to individuality and independence thoroughly can be difficult because of the basic human need of two developmental pathways. Although independent self-construal is accepted as dominant self-construal in individualistic cultures and codependent self-construal in collectivist cultures, the individual living in a culture is able to bear these self-construals at different levels (Brewer \& Chen, 2007; Triandis, 1995), and it is possible that one can develop both at the same level at the same time (Cross \& Markus, 1991). In addition, it is known that current situations in a specific culture (such as events, interactions) have the potential to awaken these self-construals and to determine which self-construal will be experienced more predominantly at that moment (Triandis, 2001; White, Darrin, \& Dov, 2006). For this reason, on one hand the individual can be autonomous and on the other hand one can continue to be attached to one's social environment (Cross \& Madson, 1997; Kağıtçıbaşı, 1996; Matsumoto, 2002). Similarly, in the literature, it is emphasized that rather than mentioning a single self-construal in individuals raised in Turkish society, there may be binary combination, coexisting of individual or relational, or triple combinations, coexisting of individual, relational and collective (Kağıtçıbaşı, 2010; Ercan, 2013). Although Turkish culture predominantly bears collectivist values in the traditional sense, it cannot be thought that there is a homogeneous structure in a culture in terms of self-construal as discussed. Studies with the samples selected from Turkey also support it (Koydemir \& Misir, 2015).

Another reason may be psychological well-being levels of individuals. In the study of Duncan, Ornaghi, and Grazzani (2013), it was found that individuals with high individual self-construal also have high levels of psychological well-being. Özdemir (2012) showed that both independent and codependent-relational self are important for the well-being of young people (life satisfaction and positive mood). This result supports the findings of our study. As individual and relational self-construal increases, psychological well-being increases as well; 
therefore, the need for psychological help decreases and this may lead to a decrease in attitudes towards receiving psychological help.

In conclusion, the variables predicting adults' attitudes towards seeking psychological help were investigated and it was found that self-stigma and individual self-construal were significant predictors. This study is limited to adults who have been studying at Pedagogical Formation Certificate Course at Trakya University Education Faculty. Working with adults studying or graduated at different universities will provide more comprehensive information on this topic in the future studies. In this study, the application was performed to the individuals in the study group without questioning whether getting any psychological help before. Self-stigma levels and self-construal of individuals who have received or applied to counseling from psychological counseling centers can be investigated in later studies. In this study, the gender of the individuals who constitute the sample group does not display a balanced distribution. Cross and Madson (1997) stated that individuals may exhibit changing traits according to their gender in the common culture in which they live, in other words, many social factors may cause the creation of various self-construal by men and women. To this respect, comparative studies in terms of self-stigma and self-construal according to gender can be conducted with different socio-cultural characteristics, especially in Turkish culture. Measurement tools developed for self-evaluation were used in this study. In-depth investigations can be conducted on the subject by using qualitative research methods in future studies.

\section{References}

Acun-Kapıkıran, N., \& Kapıkıran, Ş. (2013). Self-stigma of seeking psychological help scale: Validity and reliability. Turkish Psychological Counseling and Guidance Journal, 5(40), 131-141. https://doi.org/10.5350/dajpn2013260204

Andrews, G., Issakidis, C., \& Carter, G. (2001). Shortfall in mental health service utilisation. British Journal of Psychiatry, 179, 417-425. https://doi.org/10.1192/bjp.179.5.417

Bilge, A., \& Çam, O. (2010). The fight against stigma toward mental 1llness. TAF Preventive Medicine Bulletin, 9(1), 71-78.

Bond, M. H., \& Smith, P. B. (1996). Cross-cultural social and organizational psychology. Annual Review of Psychology, 47(1), 205-235. https://doi.org/10.1146/annurev.psych. 47.1.205

Brewer, M. B., \& Chen, Y. (2007). Where (who) are collectives in collectivism? Toward conceptual clarification of individualism and collectivism. Psychological Review, 114(1), 133-151. https://doi.org/10.1037/0033-295x.114.1.133

Cheung, R. Y. M., \& Park, I. J. K. (2010). Anger suppression, interdependent self-construal, and depression among Asian American and European American college students. Cultural Diversity and Ethnic Minority Psychology, 16(4), 517-525. https://doi.org/10.1037/a0020655

Constantine, M. G. (2001). Independent and interdependent self-construals as predictors of multicultural case conceptualization ability in counsellor trainees. Counselling Psychology 
Quarterly, 14(1), 33-42. https://doi.org/10.1080/09515070110059124

Corrigan, P. (2004). How stigma interferes with mental health care. American Psychologist, 5(7), 614-625. https://doi.org/10.1037/0003-066x.59.7.614

Corrigan, P., Roe, D., \& Tsang, H. W. H. (2011). Challenging the stigma of mental illness lessons for therapists and advocates. United Kingdom: John Wiley \& Sons Ltd. https://doi.org/10.1002/9780470977507

Cross, S. E., \& Madson, L. (1997). Models of the self: Self-construals and gender. Psychological Bulletin, 122(1), 5-37. https://doi.org/10.1037/0033-2909.122.1.5

Cross, S. E., Bacon, P. L., \& Morris, M. L. (2000). The relational-interdependent self-construal and relationships. Journal of Personality and Social Psychology, 78(4), 791-808. https://doi.org/10.1037/0022-3514.78.4.791

Duncan, E., Ornaghi, V., \& Grazzani, I. (2013). Self-construal and psychological wellbeing in scottish and Italian young adults. Journal of Happiness Studies, 14(4), 1145-1161. https://doi.org/10.1007/s10902-012-9372-0

Ercan, H. (2011). Psychometric properties and the adaptation study of the relational, individual, collective self-aspects scale. KMU Journal of Social and Economic Research, 13(21), 37-45.

Ercan, H. (2013). Genç yetişkinlerde benlik kurgusu üzerine bir çalışma. Zeitschrift für die Welt der Türken/Journal of World of Turks, 5(2), 157-178.

Helmes, E., \& Gallou, L. (2014). Culture and attitudes toward psychological help-seeking influence clients' self-disclosure. European Journal of Psychotherapy and Counselling, 16(2), 163-176. https://doi.org/10.1080/13642537.2014.895771

İmamoğlu, E. O. (1998). Individualism and collectivism in a model and scale of balanced differentiation and integration. The Journal of Psychology: Interdisciplinary and Applied, 132(1), 95-105. https://doi.org/10.1080/00223989809599268

Jorm, A. F. (2000). Mental health literacy: Public knowledge and beliefs about mental disorders. British Journal of Psychiatry, 177, 396-401. https://doi.org/10.1192/bjp.177.5.396

Kağıtçıbaşı, Ç. (1996). Autonomus-related Self: A new synthesis. Turkish Journal of Psychology, 11(37), 36-44.

Kağıtçıbaşı, Ç. (2010). Benlik, Aile ve İnsan Gelişimi: Kültürel Psikoloji. İstanbul: Koç Üniversitesi Yayınları.

Kashima, E., \& Hardie, E. A. (2000). The development and validation of the relational, individual and collective self aspects (RIC) scale. Asian Journal of Social Psychology, 3, 19-48. https://doi.org/10.1111/1467-839X.00053

Kessler, R. C., McGonagle, K. A., Zhao, S., Nelson, C. B., Hughes, M., Eshleman, S., \& Kendler, K. S. (1994). Lifetime and 12-month prevalence of DSM-III-R psychiatric disorders 
in the United States. Results from the National Comorbidity Survey. Archives of General Psychiatry, 51, 8-19. https://doi.org/10.1001/archpsyc.1994.03950010008002

Koydemir, S., \& Misır, S. (2015). Self-construals and happiness: An experimental priming study. Turkish Psychological Counseling and Guidance Journal, 5(44), 49-60. https://doi.org/ $10.14527 / 9786054282814.04$

Markus, H. R., \& Kitayama, S. (1991). Culture and the self: Implications for cognition, emotion, and motivation. Psychological Review, 98, 224-253. https://doi.org/10.1037/ 0033-295X.98.2.224

Matsumoto, D. (2002). Culture and self: An empirical assessment of Markus and Kitayama's theory of independent and interdependent self construals. Asian Journal of Social Psychology, 2(3), 289-310. https://doi.org/10.1111/1467-839X.00042

Özdemir, Y. (2012). Examination of adolescent's subjective well- being in terms of autonomous, relational and autonomous-relational self-construals. Turkish Psychological Counseling and Guidance Journal, 4(38), 188-198. https://doi.org/10.14687/jhs.v14i2.4006

Park, I. J. K., \& Kim, P. Y. (2012). The Role of self-construals in the link between anger regulation and externalizing problems in Korean American adolescents: Testing a moderated mediation model. Journal of Clinical Psychology, 68(12), 1339-1359. https://doi.org/ $10.1002 /$ jclp. 21878

Pescosolido, B. A. (1992). Beyond rational choice: The social dynamics of how people seek help. American Journal of Sociology, 97(4), 1096-1138. https://doi.org/10.1086/229863

Ryan, R. M., \& Deci, E. L. (2000). Self-determination theory and the facilitation of intrinsic motivation, social development, and well-being. American Psychologist, 55(1), 68-78. https://doi.org/10.1037/0003-066X.55.1.68

Serim, F., \& Çankaya, Z. C. (2015). The prediction of adults' psychological help seeking attitude. Ege Journal of Education, 16(1), 177-198. https://doi.org/10.12984/eed.79026

Singelis, T. M. (1994). The measurement of independent and interdependent self-construals. Personality and Social Psychology Bulletin, 20, 580-591. https://doi.org/10.1177/0146167 294205014

Su, J. C., Lee, R. M., \& Oishi, S. (2013). The role of culture and self-construal in the link between expressive suppression and depressive symptoms. Journal of Cross-Cultural Psychology, 44(2), 316-331. https://doi.org/10.1177/0022022112443413

Triandis, H. C. (1995). Individualism and collectivism. Boulder, CO:Westview Press.

Triandis, H. C. (2001). Individualism-collectivism and personality. Journal of Personality, 69, 907-924. https://doi.org/10.1111/1467-6494.696169

Trommsdorff, G., \& Rothbaum, F. (2008). Development of emotion regulation in cultural context. In M. Vandekerckhove, C. von Scheve, S. Ismer, S. Jung, \& S. Kronast (Eds.), Regulating emotions: Culture, social necessity, and biological inheritance (pp. 85-120). 
Malden, MA: Blackwell. https://doi.org/10.1002/9781444301786.ch

Türküm, A. S. (2000). The development of Coping with Stress Scale: Validity and reliability studies. Turkish Psychological Counseling and Guidance Journal, 2(18), 25-34. https://doi.org/10.14527/9789756802656.08

Türküm, A. S. (2001). The relationships among coping with stress, optimism, irrational beliefs and attitudes towards seeking psychological help: A study with university students. Anadolu University Journal of Social Sciences, 1, 1-16. https://hdl.handle.net/11421/562

Vauth, R., Kleim, B., Wirtz, B., \& Corrigan, P. W. (2007). Self-efficacy and empowerment as outcomes of selfstigmatizing and coping in schizophrenia. Psychiatry Research, 150, 71-80. https://doi.org/10.1016/j.psychres.2006.07.005

Vogel, D. L., Bitman, R. L., Hammer, J. H., \& Wade, N. G. (2013). Is stigma internalized? The longitudinal impact of public stigma on self-stigma. Journal of Counseling Psychology, 60(2), 311-316. https://doi.org/10.1037/a0031889

Vogel, D. L., Wade, N. G., \& Haake, S. (2006). Measuring the self-stigma associated with seeking psychological help. Journal of Counseling Psychology, 53(3), 325-337. https://doi.org/10.1037/0022-0167.53.3.325

White, K, Darrin, R. L., \& Dov, C. (2006). Culture, self-construal, and affective reactions to successful and unsuccessful others. Journal of Experimental Social Psychology, 42(5), 582-92. https://doi.org/10.1016/j.jesp.2005.10.001

Yalçın, İ. (2016). The Role of Self-Construal and Perceived Social Support in Prediction of Attitudes Toward Seeking Professional Psychological Help. Education and Science, 41(183), 339-349. https://doi.org/10.15390/eb.2016.3083

\section{Copyright Disclaimer}

Copyright for this article is retained by the author(s), with first publication rights granted to the journal.

This is an open-access article distributed under the terms and conditions of the Creative Commons Attribution license (http://creativecommons.org/licenses/by/3.0/). 